\title{
Chapter 15 \\ Mitigating Slipping-Related Mortality from Purse Seine Fisheries for Small Pelagic Fish: Case Studies from European Atlantic Waters
}

\author{
Ana Marçalo, Mike Breen, Maria Tenningen, Iñigo Onandia, Luis Arregi, \\ and Jorge M. S. Gonçalves
}

\begin{abstract}
The release of unwanted catches (UWC) from purse seines, while the catch is still in the water, is known as "slipping". Once thought to be a benign process, compared to discarding UWC overboard from the fishing vessel, it is now recognised that "slipping" can lead to significant mortality in the released fish if done inappropriately. In this chapter, we examine purse seining and slipping operations, and discuss what drives slipping and potential mitigation measures to reduce slipping mortality. We use three examples of purse seine fisheries for small pelagic species in the North-east Atlantic; from Norway, Portugal and Spain. The ideal solution (identifying and avoiding UWC before the net is set) requires the development of tools to enable fishers to better characterise target schools in terms of key selection criteria, e.g., with respect to species, individual size and catch biomass. Such tools are being developed, based primarily on hydro-acoustic technology. However, some UWC in purse seine catches are inevitable, and operational improvements in slipping practices have been shown to significantly reduce stress and mortality in the released UWC. We conclude with a discussion on the challenges currently facing the implementation of the European Union (EU) Landing Obligation with regards to minimising slipping related mortality.
\end{abstract}

Keywords Bycatch and slipping mitigation - Delayed mortality · Pelagic fish · Purse seine

\footnotetext{
A. Marçalo $(\varangle)$. J. M. S. Gonçalves

Centro de Ciências do Mar-CCMAR, Universidade do Algarve, Faro, Portugal

e-mail: amarcalo@ualg.pt
}

M. Breen $(\bowtie) \cdot M$. Tenningen

Institute of Marine Research (IMR), Bergen, Norway

e-mail: michael.breen@hi.no

I. Onandia $\cdot$ L. Arregi

AZTI, Txatxarramendi ugartea z/g, Sukarrieta, Bizkaia, Spain 


\subsection{Introduction}

Purse seining is a fishing method for targeting large (e.g. tunas) and small species (e.g. mackerels, sardines and anchovies) that school or aggregate close to the surface. It has been the most productive fishing method throughout the world for the past six decades, accounting for approximately one third of the global catch by weight (Watson et al. 2006). Incidental catches of dolphins first raised awareness of bycatch issues in tuna purse seine fisheries; although unwanted catches (UWC) of some species and sizes of teleosts, including undersized tunas and some species of elasmobranchs, are also common for these fisheries (Hall et al. 2000; Kelleher 2005; Megalofonou et al. 2005; Hall and Roman 2013). Purse seine fisheries target catches of low species and size diversity, which contributes to a sporadic occurrence of UWC (Broadhurst et al. 2006; Borges et al. 2008), but reported rates of UWC are usually low, and spatially and temporally variable (i.e., 3.5\% for tuna fisheries, Gilman et al. 2017; and 1.6-27\% for small pelagic fisheries, Kelleher 2005; Borges et al. 2001).

Purse seines, particularly for small species, are generally considered to be a non-selective fishing gear once a target school has been encircled, primarily because of the small mesh sizes used in the main body of the net, typically $<20 \mathrm{~mm}$. Therefore, the release of UWC generally happens in one of two ways: firstly, by "slipping" all or part of the UWC out of the net while it is still in the water; or secondly, by "discarding", when the catch is taken aboard and any unwanted components are removed and returned to the sea alive or dead. As with other fisheries, "discarding" is associated with an array of potentially fatal stressors for the affected animals, and the likelihood of survival is generally assumed to be low (e.g. Davis 2002; Breen et al. in review).

Conversely, because the catch never leaves the water, "slipping" was once assumed to be a benign method of releasing UWC from the net, without harming it. However, experiments have demonstrated that "slipping" of small pelagic species like mackerel (Scomber scombrus) (Lockwood et al. 1983; Huse and Vold 2010), herring (Clupea harengus) (Tenningen et al. 2012), sardine (Sardina pilchardus) (Marçalo et al. 2006; Marçalo et al. 2010) and sardinops (Sardinops sagax) (Mitchell et al. 2002) may result in unacceptably high rates of mortality. Some of this research has shown that during the final phase of the capture process, the catch can become highly crowded, with densities $>250 \mathrm{~kg} . \mathrm{m}^{-3}$ (Tenningen et al. 2012), and can be exposed to potentially fatal stressors, including hypoxia, exhaustion and physical injury from contact with the net and catch. This established that the mortality of slipped fish is directly related to their treatment within the net, with mortality increasing with increasing crowding densities and crowding time (Lockwood et al. 1983; Tenningen et al. 2012; Marçalo et al. 2010). This concern about slippingrelated mortality has led to recent regulations in some European fisheries that ban the practice of slipping, unless the released fish can survive [e.g. EU Landing Obligation (EU 2013); Norwegian Seawater Fisheries Regulations (NSFR 2014]. 
In this chapter we review purse seine fishing targeting small pelagic species in the North East Atlantic, with reference to mitigating slipping-related mortality. We will use three different purse seine fisheries (Norwegian coastal and offshore; Spanish Cantabrian Sea and North-western waters; and Portuguese sardine fishery) as case studies to explore the following topics:

- Case study overviews including fishing operations and slipping practices;

- Mitigation measures to minimise slipping related mortality; and

- Challenges currently facing the implementation of EU Landing Obligation with regards to minimising slipping related mortality.

\subsection{Purse Seine Fishing Targeting Small Pelagic Species in the Atlantic}

\subsubsection{Overviews of Case Studies}

Three case studies of purse seine fisheries for small pelagic species in the NE Atlantic are briefly reviewed here.

\subsubsection{Norwegian Inshore and Offshore Fisheries}

Close to 400 purse seine vessels operate in Norway (Table 15.1), which account for about $30 \%$ of Norway's total annual landings (Norwegian Directorate of Fisheries 2018). Most of the vessels are relatively small coastal purse seiners $(15-55 \mathrm{~m}$ length), but about $65 \%$ of the catch is taken by 73 large ocean-going purse seiners (Table 15.1). Mackerel, herring and capelin (Mallotus villosus) are the main target species, and in 2017 about 800,000 tonnes were captured (of which 63,000 t taken in the EU Zone) with a landed sale value of $€ 490 \mathrm{M}$.

\subsubsection{Spanish Cantabrian Sea and North-West Fisheries}

Purse seine landings in this fishery are estimated at 170,450 tonnes, representing $37 \%$ of the total landings by the fleet operating in EU waters (STECF 2017), with a value of more than $€ 140 \mathrm{M}$. Purse seining employs 6276 fishers out of a total of 28,078 employed in fisheries in Spanish waters (MAPAMA 2017). Five main Spanish purse seine fisheries can be identified in the fishing area, here we focus on the purse seine fisheries in the Cantabrian Sea and North-west targeting small pelagics (Table 15.1). 


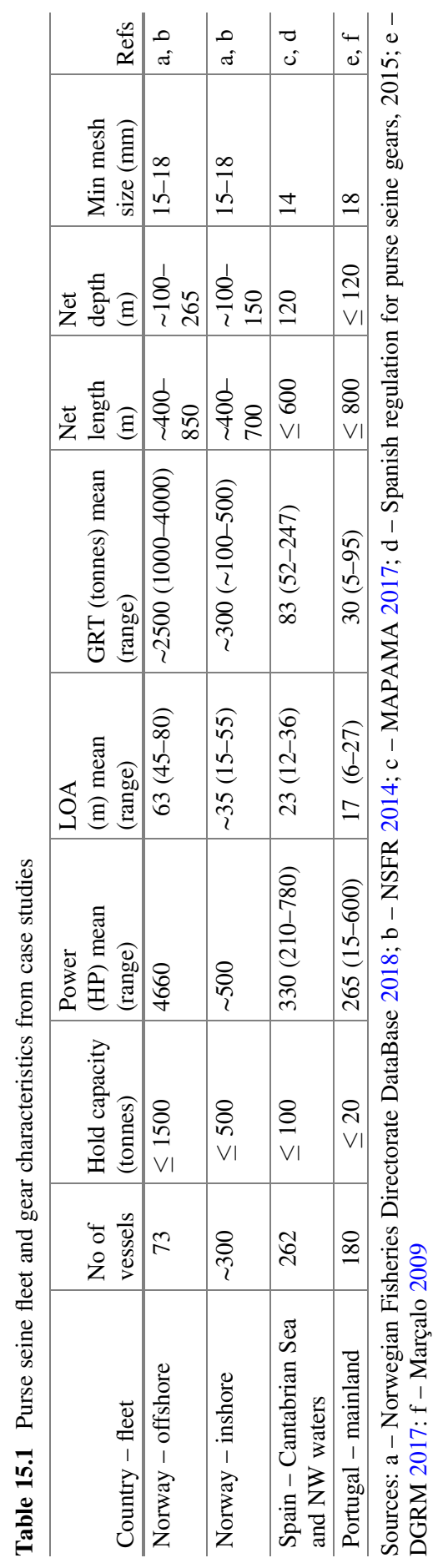




\subsubsection{Portuguese Sardine Fishery}

The Portuguese sardine fishery accounts for about $50 \%$ by weight of catches landed in the country's mainland ports (DGRM. DATAPESCAS 2017). The fishery is coastal (operating within the continental shelf), and the fleet is comprised of 180 vessels (Table 15.1). Sardine is the target species and accounts for more than $90 \%$ of total catch weight and value (Silva et al. 2015). Horse mackerel (Trachurus trachurus), chub mackerel (Scomber colias) and anchovy (Engraulis encrasicolus) account for a smaller part of the landings (Stratoudakis and Marçalo 2002; Feijó et al. 2018). Landings in 2017 were 45,488 tonnes with a value of more than $€ 51 \mathrm{M}$ (DGRM. DATAPESCAS 2017).

\subsubsection{Purse Seine Fishing Operations}

Once a potential target school has been located, typically using hydro-acoustic fish detection technology (e.g. sonar and echo-sounders), it is quickly surrounded by a wall of netting. The net is supported at the surface with a float-line, while at the bottom, a heavy, "leaded" rope and a series of heavy metal rings ("purse rings") ensures the net sinks quickly around the catch (Fig. 15.1a). The purse seine is typically set rapidly ( $\sim 10$ mins) by a single vessel, although in Portugal a small auxiliary vessel ("skiff"; 6-7 meters) assists in the operation. When the net has been fully deployed, or "set", a wire rope, or "purse line", that passes through the purse rings is then pulled into the vessel, closing the net beneath the school to prevent the fish from diving and escaping (Fig. 15.1b). The net is then gradually hauled in using hydraulic winches (e.g. a Triplex Power block), which progressively reduces the volume contained by the net, and crowds the catch into the bunt end (Fig. 15.1a) until the density becomes sufficiently high to inspect what is in the catch. In Portugal and Spain this final stage of hauling, as the fish are crowded in the bunt, is often done manually (i.e., with the crew hauling the net aboard the vessel by hand). After the catch is inspected, if the decision is made to harvest it, it is then transferred into the boat; either by brailing (i.e., using large dip nets called brails in Portugal and Spain) or using fish pumps (in Spain and Norway), while the rest of the catch is left in the water.

There are substantial differences between fleets with respect to individual catch sizes, as well as vessel and gear dimensions (Table 15.1). Catches in the Spanish and Portuguese fisheries are typically around 3-5 tonnes, but can exceed 10 tonnes, while in the Norwegian fisheries they are typically much larger (50-500 tonnes) and can exceed 1000 tonnes. The most striking difference between the fleets is the size range and hold storage capacity of the vessels, with the Norwegian offshore fleet dwarfing those of the other fleets. In contrast, differences in net dimensions among fleets are comparatively small. 
a

Float-line



b
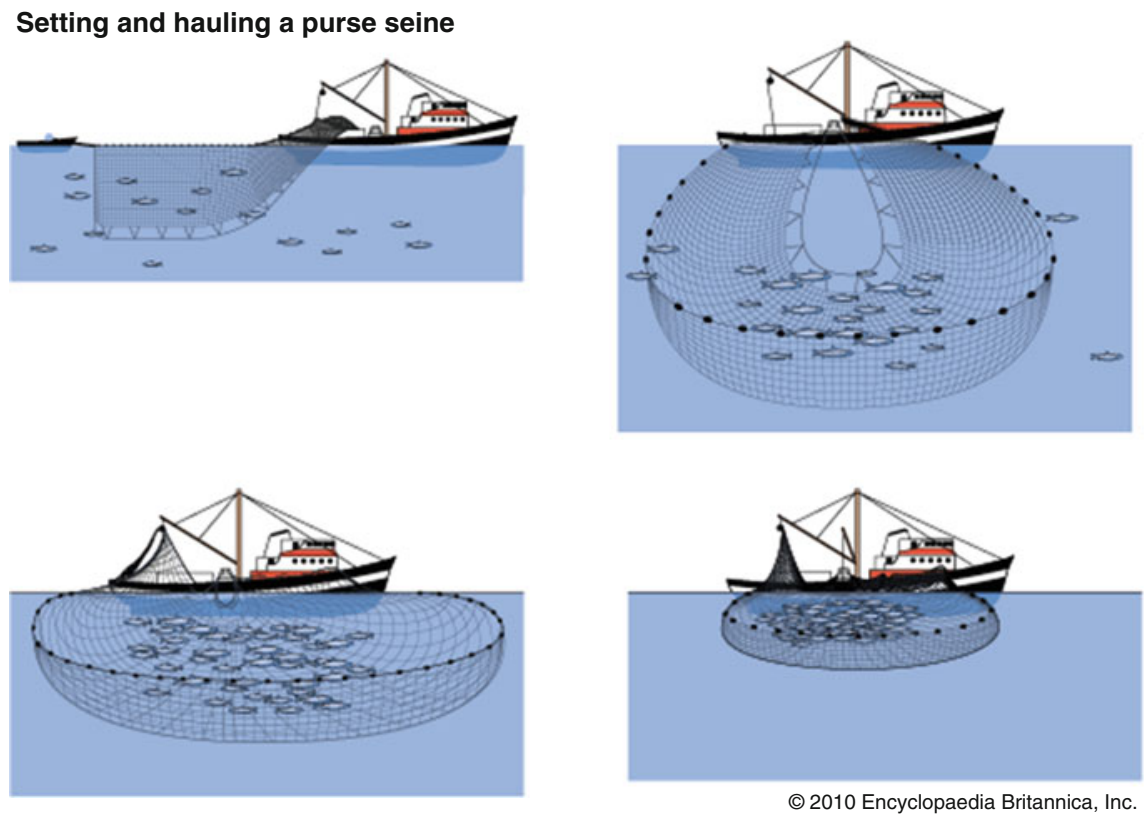

Fig. 15.1 Diagram of a purse seine net: (a) principal components) and (b) purse seining operations: setting the net and hauling

\subsubsection{Slipping Practices - Drivers and Methods}

As with many fisheries, UWC in purse seine fisheries can result from a variety of economic (i.e., catch quality, market price/demand) and regulatory (i.e., quotas, sizes, protected species) drivers that may result in the catch being slipped. In addition, due to the dimensions of the net and the nature of the target species to form large and sometimes dense schools, purse seining can take catches far in excess of the holding capacity of the fishing vessel. This issue is particularly relevant for smaller vessels, which may only have the capacity to retain a proportion of the catch in the net (Table 15.1). 

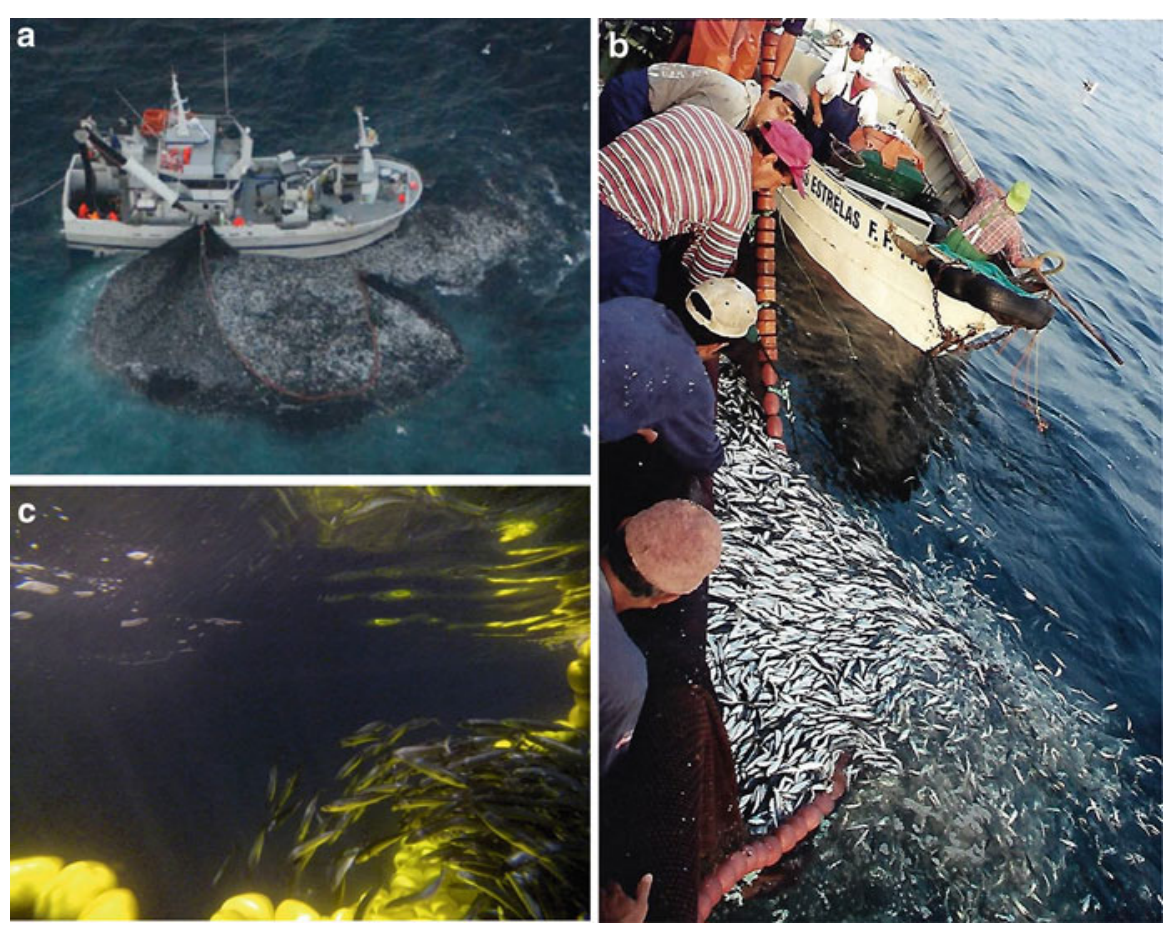

Fig. 15.2 Slipping operations in different purse seine fisheries: (a) Norwegian; (b) Portuguese; (c) Spanish

\subsubsection{Norwegian Fisheries}

In Norway, it is legal to release viable UWC from purse seine, but the vessels have individual transferrable quotas (ITQ) to purposely reduce regulatory pressures to discard (Gullestad et al. 2015). Furthermore, all pelagic fish sales are controlled by a single authority ("Norges Sildesalgslag"), so landings (including bycatch) from individual boats are closely monitored and controlled. While economic drivers may also influence slipping practices, it is generally felt that at present the main driver for slipping in the Norwegian fleet is catch size, particularly amongst the coastal fleet. However, there are currently no reliable estimates of the magnitude or frequency of these slipping events.

With regard to slipping practices, fishers' behaviour is now, in principle, driven by regulations governing such practices in Norwegian and EU waters. Before the introduction of these regulations, unwanted or excessive catches were released late in the capture process, when the catch was very crowded, by slipping over the floatline, or by partially opening the bunt-end as the net was hauled aboard (Fig. 15.2a). In 2014, regulations were introduced to manage slipping practices in mackerel fisheries in Norwegian waters. The regulations prescribe that the seine must be prepared for release of UWC (i.e. bunt-end opened) before $7 / 8$ of the net length is 
hauled (marked by a visible float), and UWC must be released through an opening sufficiently large to permit the fish to swim out freely (NSFR 2014; Rule §48a). Following the introduction of the EU Landing Obligation (LO), slipping practices in EU waters were regulated from 2015 by Commission Delegated Regulations (CDRs), for both North-Western Waters and the North Sea (EU 2014a, b). These enact High Survival Exemptions (HSE) to the LO (see Chap. 3 for more details; Rihan et al., this volume) for herring and mackerel fisheries, provided the catch is released before a certain proportion of the net is hauled, referred to as the "point of retrieval", (also marked by a visible float); where the limits are $80 \%$ of the net for mackerel; and $90 \%$ for herring. Furthermore, the vessel and purse seine should be equipped with electronic instruments to document when, where and the extent to which the purse seine has been hauled.

\subsubsection{Spanish Fisheries}

In the Cantabrian and NW Spanish waters, anchovy is slipped due to the low market price of small-sized individuals and fish under the Minimum Conservation Reference Size (MCRS), while mackerel and horse mackerel are slipped when their quotas are exhausted. On the other hand, sardine (ICES divisions 8a, b and d) and Atlantic chub mackerel have no quota limitations, but they may be discarded due to low market prices. From observer data in these fisheries, the frequency of slipping events was estimated to be $8.3 \%$ (17 slipping events in 204 sets) (Arregi et al. unpublished data).

The South Western Waters' purse seine fisheries (Portuguese, Spanish and French) are permitted to slip several species (mackerel, horse mackerel, and anchovy) under a High Survival Exemption (HSE) in the EU Commission Delegated Regulation (CDR) for South Western Waters (EU 2014c; Rihan et al., this volume). Furthermore, the conditions of this HSE recognise the small-scale nature of purse seine operations in these fleets and is far less prescriptive in its conditions for slipping practices, stating: "[...] catches may be released, provided the net is not fully taken aboard". The slipping method differs from other fisheries, where fishers will roll the fish over the headline. Here, the bunt and the first 5 to 10 pursing rings are detached and the catch is released before it becomes too crowded (Fig. 15.2c). Catches from this fleet are used fresh, for human consumption, so quality is an important factor. This influences how the fishers handle the catch, where crowding density is kept under about $80 \mathrm{~kg}$ of fish per cubic metre to avoid abrasion and crushing of the catch.

\subsubsection{Portuguese Sardine Fishery}

The Portuguese sardine fishery is currently affected by a historically low spawning stock biomass for the southern-Iberian stock, which is below safe biological limits (Silva et al. 2015). This led to strict management measures (e.g. seasonal ban and 
daily quotas per vessel), which have been applied by the Portuguese government since 2012 (Silva et al. 2015) and ICES recommending a zero TAC since 2018 (ICES 2018). As with Norway, all landings and sales are handled through a single national authority (DocaPesca). So, during the sardine ban, fishers are targeting other pelagic species, including Atlantic chub mackerel and horse mackerel; and slipping sardine, if caught. Conversely, during the open sardine season there is an increased slipping of other species (due to the high market prices for sardine), but also excess sardine, because daily sardine quotas are very small (usually around 1.5-2.0 tonnes per vessel). However, neither sardine nor chub mackerel are currently listed amongst the species in the HSE for SW waters (EU 2014c). Other drivers for slipping in this fishery may be: vessel capacity the presence of non-commercial species, undersized fish, or a mixture of species, which will devalue the catch at auction (Stratoudakis and Marçalo 2002; Marçalo 2009; Feijó et al. 2018). The slipping practice typically occurs at the very end of the fishing operation and involves rolling the fish over the float-line (Fig. 15.2b).

\subsection{Mitigation Measures to Reduce Slipping Related Mortality}

To effectively reduce slipping-related mortality, it is necessary to release any unwanted catch as early in the capture process as possible, before the fish become fatally stressed. To do this the fisher requires tools and methods to: (a) characterise the potential catch so that the decision to take or release it can be made as early in the capture process as possible, ideally before the net has even been set; and, (b) where slipping is unavoidable, release any unwanted catch in a controlled way with minimal stress to the fish (Breen et al. 2012; Breen et al. in review; CRISP 2018). Here, we describe research in three main areas of development that aims to provide such tools: (1) pre-catch identification of fish schools (with respect to species, quantity and fish size) using hydro-acoustic methods to prevent catching unwanted fish; (2) monitoring the catch and net during the haul to provide information on the catch density, fish size and quality at an early stage in the haul, while slipping is still acceptable; and (3) modifications to purse seine design and practices to promote the survival of slipped fish (Fig. 15.3).

\subsubsection{Pre-Catch Identification - Minimize the Need for Slipping}

Skippers use experience and knowledge about the behaviours of different species to evaluate school size and species based on received echoes on their sonar and echosounder screens. However, having accurate quantitative estimates of school characteristics will further improve catch estimation and reduce UWC. Furthermore, 


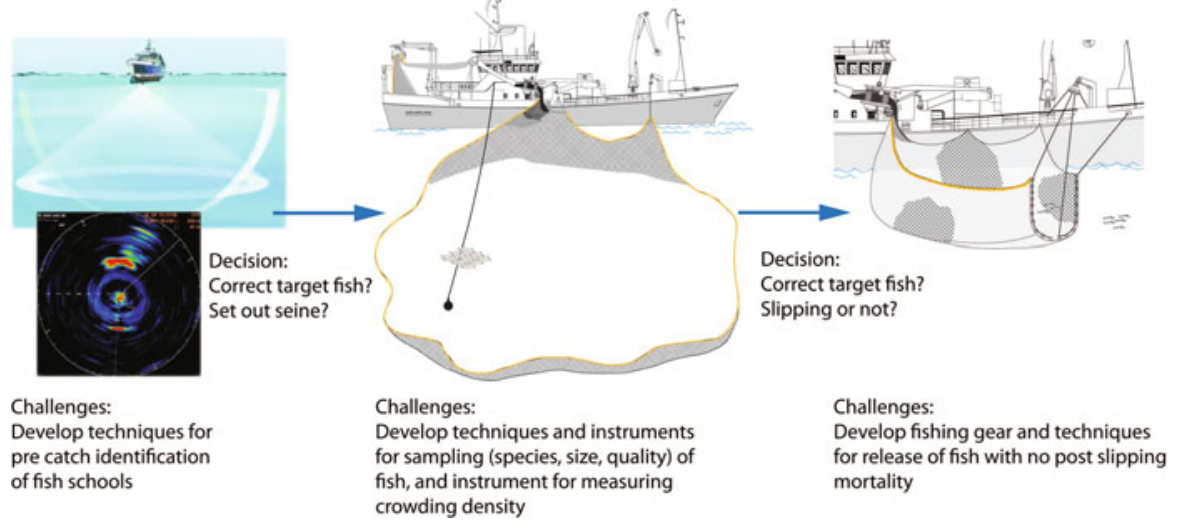

Fig. 15.3 The three-stage strategy to provide purse seine fishers with the tools and methods necessary for avoiding unwanted catches and reducing slipping-related mortality. (From Breen et al. 2012)

avoiding UWC can have significant economic benefits for fishers, through reduced fuel costs and improved catch quality and prices (Larsen and Dreyer 2013). Information about the species in a school, school morphology and geographical distribution can, to some degree, be estimated using multi-frequency echo-sounders (Horne 2000; Korneliussen et al. 2009). The echo strengths at different frequencies are species-specific, due to variation in fish morphology (e.g. presence or absence of a swimbladder) and the relative frequency response $r(f)$, i.e. the ratio of the backscattered energy at frequency $f$ to that at $38 \mathrm{kHz}$, can be used to distinguish between some species. Individual fish size within a school can also be estimated using a high resolution broadband echo-sounder, if individual targets can be detected (CRISP 2018). In recent years, significant progress has also been made in using multi-beam sonars to quantify fish school sizes (Nishimori et al. 2009; Vatnehol et al. 2017) and behaviour (Gerlotto and Paramo 2003; Holmin et al. 2012). In Norway, research and development in hydro-acoustic pre-catch identification is a well-functioning cooperation between research institutes, the fishing industry and companies delivering fisheries instrumentation (e.g. CRISP 2018; LSSS 2018; DABGRAF 2018; SEAT 2018).

\subsubsection{Early-Catch Monitoring}

Nevertheless pre-catch identification is not always accurate, especially when schools are large and dense. So, it is also necessary to have tools to monitor and characterise the catch early in the capture process before the fish become too crowded in the net. However, monitoring a school inside the net is challenging, even using acoustic 


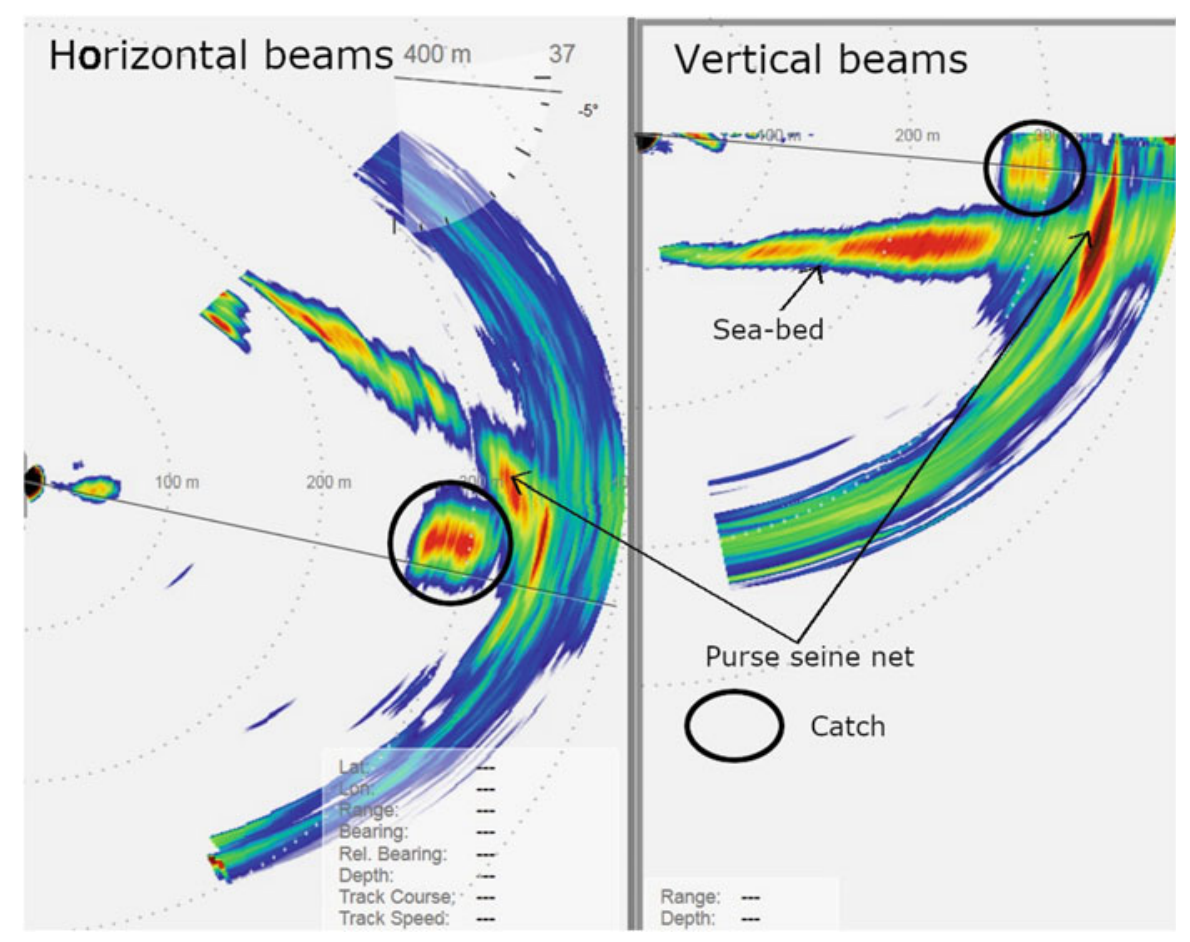

Fig. 15.4 Image from the Simrad SN90 sonar (Kongsberg Maritime AS) of a school of North Sea herring in a purse seine, with the wall of the net clearly visible. Left panel - horizontal view; right panel - vertical view

technologies. Omnidirectional sonars are usually retracted into the hull during purse seining to avoid damage, making them unsuitable for monitoring schools during capture. But multi-beam sonar, mounted on a research vessel, has been used to monitor and describe the behaviour of schools captured by purse seine (Tenningen et al. 2017). Multi-beam sonars on fishing vessels, with side-looking transducers are now commercially available (e.g. Kongsberg Maritime SN90) so work is in progress to obtain a better understanding of fish behaviour, densities and school biomass inside the seine (Fig. 15.4).

Multi-beam sonar has also been used to describe purse seine shape and volume during seine hauling (Tenningen et al. 2015). This work has provided a better understanding of how the volume available for captured fish schools varies under different fishing conditions and the impact that may have on the survival of slipped fish.

In addition to acoustic methods, efforts have been made to develop tools for obtaining sub-samples of catches, monitoring the catch visually and collecting data on environmental conditions in the net. However, this is technically challenging because the seine is large and dynamic, making it difficult to attach any monitoring instruments to it directly. Examples of promising methods include: a small sampling 


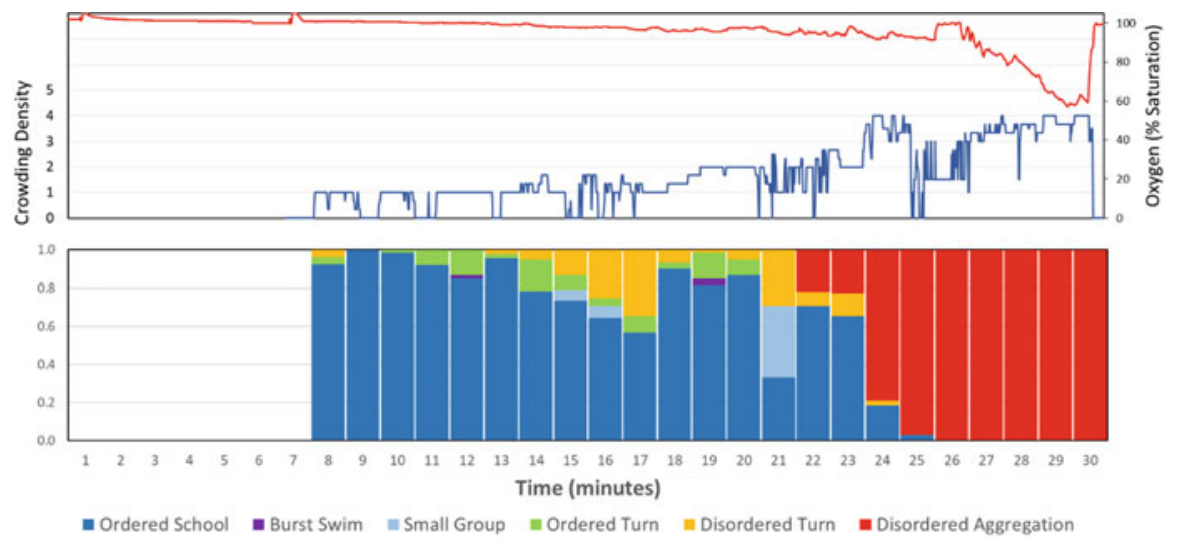

Fig. 15.5 An example from a single commercial purse seine cast showing that crowding density (blue line; ordinal score) and dissolved oxygen concentration (red line; \% saturation) (top), and behaviour (below), changed over time (Behaviour summarised in 1 min bins). (From Breen et al. in prep)

trawl, deployed using a pneumatic canon (Isaksen 2013; Peña et al. 2018); a monitoring probe deployed in the same way and equipped with cameras and instruments for measuring oxygen, temperature and depth (Breen et al. in prep); and measuring the size frequency distribution inside the catch with a stereo-camera (see SINTEF FKiN Project 2018).

\subsubsection{Late Capture and Release}

Research has demonstrated that slipping unwanted catches from the purse seine can be a responsible catch control practice, if done before the captive fish become too crowded and in a way that maintains their ordered behaviour. For example, in controlled experiments, mackerel could tolerate moderate crowding densities $\left(\sim 88 \mathrm{~kg} \mathrm{~m}^{-3}\right.$ for up to $\left.1 \mathrm{~h}\right)$ and relatively low oxygen concentrations $(\sim 40 \%$ saturation) without significant mortality (as observed up to 8 days after stressor treatment) (Handegard et al. 2018). Furthermore, preliminary observations suggest that such conditions do not develop in commercial catches until late in the haul-back phase, particularly in slipped catches (Breen et al. in prep; Fig. 15.5). In addition, changes in behaviour have been observed at sub-lethal and potentially lethal crowding densities that could be used as potential indicators of stress in the catch, but practical challenges for effectively monitoring such indicators remain (Breen et al. in review).

Amongst our case studies, there are several examples of research demonstrating the effectiveness of good slipping practices in reducing stress and promoting survival in released catches. 


\subsubsection{Norwegian Fisheries}

A practical code of "best practice" for conducting slipping operations was developed in collaboration with the fishing industry and Norwegian Fisheries Directorate (Vold et al. 2017). This "best practice" includes recommendations for using the bunt-end of the net to form a controllable release opening (with minimum dimensions, i.e. length $>18 \mathrm{~m}$ ), from which the fish can be allowed to swim freely. The effectiveness of this "best practice" was assessed in context with the regulation, which require that fish swim freely from the net. So, the behaviour of the released catch (herring and mackerel) was observed during slipping, in relation to the dimension and form of the release opening, as well as other operational parameters. It showed that initially the fish were reluctant to leave the net but eventually, once the catch began to swim out of the net, they typically retained an ordered schooling behaviour. However, some disordered behaviour was observed as well, and this typically occurred later in the slipping process and was more likely to be seen in larger catches (Vold et al. 2017).

\subsubsection{Spanish Cantabrian and NW Fisheries}

To assess whether different components of UWC could be released without a significant slipping mortality, the survival of several species (mackerel, horse mackerel, anchovy, sardine and Atlantic chub mackerel) was assessed after exposing them to different crowding periods (0-50 min) during commercial purse seine operations. Several experiments were done (in 2013/14) aboard vessels that alternated purse seine with pole and line targeting tunas during summer. These vessels were equipped with several large water tanks $\left(\sim 10 \mathrm{~m}^{3}\right.$, water replacement rate $\left.4001 . \mathrm{min}^{-1}\right)$ specifically designed to maintain live bait (caught with the vessel's purse seine gear) and thus provide a useful facility for this research. Sub-samples of the catch, using a fish pump, were taken at different time intervals after the catch had been crowded in the bunt, and then behaviour and survival of the fish was monitored in the "live-bait" tanks for between 2 and 6 days. The results generally showed high survival rates (horse mackerel: 89.7-100\%; anchovy: 54.2-97.8\%; sardine: 83.9-100\%; and Atlantic chub mackerel: $100 \%$ ); but for mackerel a large range: $3-100 \%$. These results were presented as supporting evidence for a successful application for a HSE (STECF 2014; EU 2014b). However, there was considerable variability, particularly with respect to species, crowding time, crowding density and catch size (Fig. 15.6). Furthermore, following advice from the ICES Workshop on Methods for Estimating Discard Survival (WKMEDS; ICES 2016) work is ongoing to substantiate these results with experiments using longer monitoring periods (up to 20 days), to avoid underestimating mortality (ICES 2018; in press; see also Rihan et al., this volume). 




Fig. 15.6 Post-crowding survival of five small pelagic species (mackerel, horse mackerel, chub mackerel, anchovy and sardine) subsampled from Spanish purse seines after different time intervals (0-50 min). (From Arregi et al. unpublished data)

\subsubsection{Portuguese Sardine Fishery}

Previous research in this fishery showed that survival of released sardines was likely to be greater during earlier stages of the hauling phase, when crowding was less (Marçalo et al. 2010). During meetings with fishers to discuss practical methods to mitigate the slipping problem, it was suggested that during the closed season, sardines could be released from the remainder of the catch through an opening created by putting weights over the float-line. This utilised differences in the behaviour of different species in the catch to selectively release the sardines. That is, sardines when in a mixed catch with other small pelagic species, usually swim close to the surface, while other species (e.g., chub mackerel) swim down in the net. Experiments were done to assess the effectiveness of this method in promoting the survival of slipped sardines, compared to the standard method of rolling the fish over the float-line and a control (non-slipped and non-crowded sardines) (Fig. 15.7; Marçalo et al. 2018). After transferring samples of released and control fish to onshore aquaria, survival rates were monitored in captivity for 28 days. Survival (at asymptote) of sardines in the three replicates from the standard slipping was low $(12.8 \%$; $8.9-15.2$ at $95 \% \mathrm{CI})$, however the modified slipping procedure did significantly improve survival (survival at asymptote of $44.7 \% ; 39.3-50.1 \%$ at $95 \% \mathrm{CI}$ ), which was comparable to the control fish (survival at asymptote of $43.6 \%$; $38-0-49.3$ at $95 \% \mathrm{CI})$. 




Fig. 15.7 Diagram of sampling at sea for the control, modified and standard slipping techniques in the Portuguese purse seine MINOUW case study (in Marçalo et al. 2018)

\subsection{Challenges for the Landing Obligation in Regulating Slipping in Purse Seine Fisheries}

In this chapter, we have reviewed slipping in three NE Atlantic purse seine fleets operating in small pelagic fisheries. This has shown that there are several issues driving slipping practices, including economic (e.g., market value) and regulatory (e.g., quotas, MCRS) pressures. For purse seine fishing, there is an additional driver, i.e., the capacity for vessel to hold excessively large catches. Furthermore, there are substantial differences across the described fleets with respect to individual catch composition and sizes, vessel power and capacity. The Norwegian offshore fleet is characterised as having relatively new and large vessels and has invested considerably in the latest fish finding (hydro-acoustic), gear handling and catch storage technologies, compared to the smaller vessels in the Norwegian (coastal), Portuguese and Spanish fleets. This diversity in fishing practices, resources and investment, as well as regional economic and social difficulties, will differentially affect slipping practices and has been cited as a major challenge for introducing the Landing Obligation in some EU Member States (Veiga et al. 2016; Maynou et al. 2018).

Various operational and technological solutions are described in this chapter (some still being developed) which have the potential to promote the survival of unwanted catches released from purse seine fisheries. As with many fisheries, the ideal solution for dealing with UWC is to avoid catching it in the first instance (see O'Neill et al., this volume; Reid et al., this volume). In purse seining, this means providing the fisher with the tools to characterise the catch (in terms of species composition, quality/size range and catch volume) before setting the seine, or at least early in the capture process. For this, hydro-acoustic technologies are being examined as the most promising technological solution, with the potential for describing species composition, size frequency distribution and catch biomass. However, we also identified several novel methods (e.g., the canon-deployed sampling trawl) that 
could provide "low tech" and more affordable solutions for at least partly characterising the catch before it is fully crowded next to the boat.

In most fisheries at present it is not until the catch is inside the net, and at least partially crowded, that the fisher has enough information to be able to decide to bring the catch on board or not. If the fisher is legally obliged to take the catch onboard, even if it entirely or partly consists of UWC, this can present him/her with several challenges, particularly if the vessel is small. Firstly, assuming the vessel has the capacity to take the catch onboard, storage space may be limited making it difficult to keep the UWC separate from the marketable catch, as required by the LO (Villasante et al. 2016a, b). Furthermore, there is currently no on-shore infrastructure for accommodating and processing the UWC - at least in most southern European Member States (Veiga et al. 2016; Maynou et al. 2018). More critically, if a vessel does not have the capacity to take all of the catch on board, the fisher is presented with a serious dilemma that could threaten the safety of his/her vessel and crew. There are examples of fisheries where the catch in such cases is shared between nearby vessels (e.g., in Portugal and Spain; Feijó et al. 2018). However, the delay associated with transferring the catch to other vessels has been linked with a substantial reduction in catch quality, and hence price (Digre et al. 2016). Thus, this presents the manager with the challenge of how to regulate/incentivise such practices to ensure the vessel receiving the excess catch is suitably compensated.

Several studies in this chapter have shown that, provided that the catch does not become too crowded, it can be released in a viable state with a high likelihood of survival. Each of these methods relies on providing a suitably large opening in the net to allow the fish to swim out before they become too crowded and for too long (Fig. 15.8). Furthermore, in the case of the Portuguese fishery, it was also shown that sardine could be released selectively, while retaining other components of the catch, because of behavioural differences between species when captive in the net (Marçalo et al. 2018). If the whole catch is to be released, this is a relatively simple operation, as demonstrated in the Spanish fishery, whereby the bunt end/wing is opened and several purse rings are released. However, if only a proportion of the catch is to be released, more control over the opening and release process is required. Furthermore, there is likely to be a critical point during the slipping process, after which the fish have become too stressed and their survival will be compromised. How this release process can be effectively and safely monitored and controlled to ensure that only viable fish are released remains a considerable challenge.

The EU Landing Obligation (LO) recognises that regional and fisheries specific differences in UWC will require tailored solutions, which can be facilitated through Commission Delegated Regulations (CDRs), and include exemptions like the High Survival Exemption (HSE) (Rihan et al., this volume). Particularly relevant to the slipping problem is the HSE, because if a fishery can demonstrate to the EU Commission that any released UWC has a high likelihood of survival, it may be exempted from the LO. Comparable regulations also apply in Norway (Karp et al., this volume). Unfortunately, there are disparities in some of these regulations that present fishers with some considerable challenges. For example, in the EU CDR for pelagic fisheries in SW waters (EU 2014a, b, c), a HSE has been granted to release 
Fig. 15.8 View from beneath the vessel as a school of herring swims out of a purse seine during slipping. [Source: IMR]

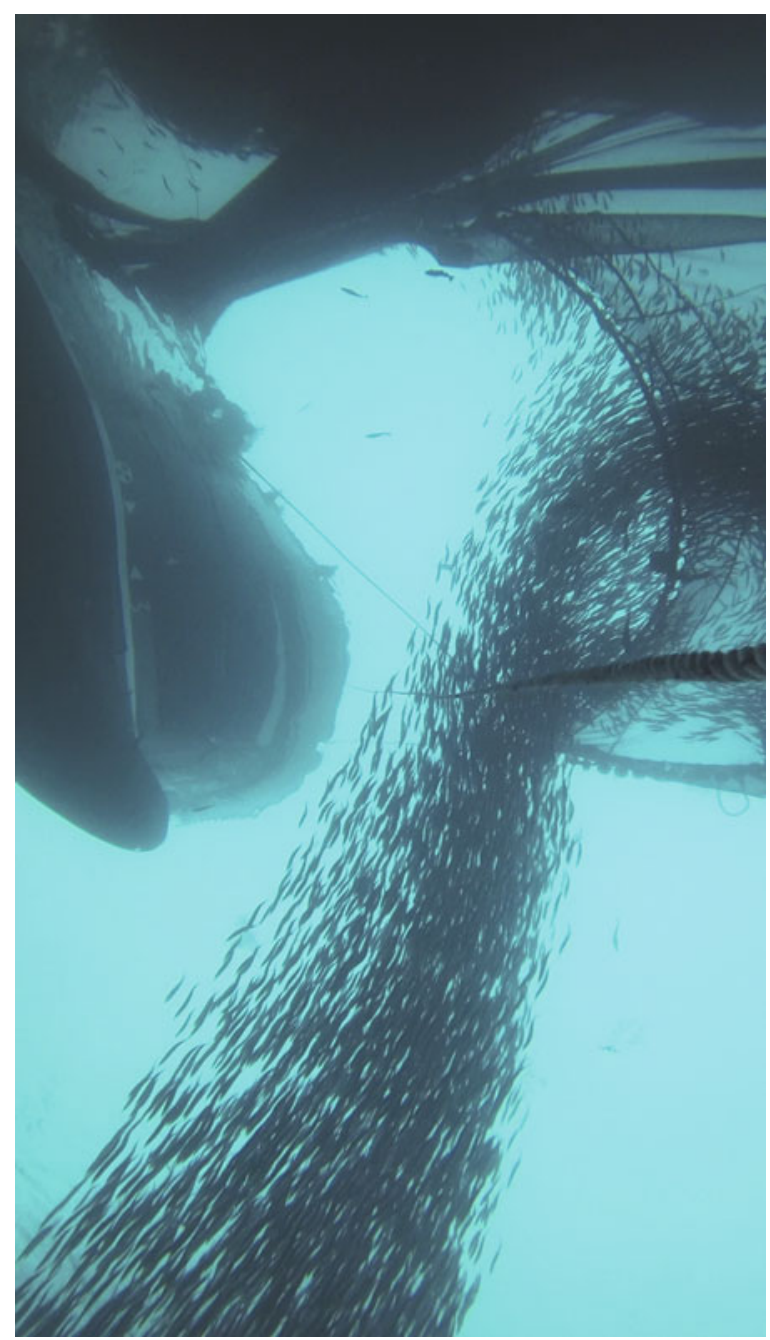

unwanted catches of anchovy, mackerel, horse mackerel and jack mackerel. Excluded from this exemption is sardine, despite data being available when the HSE was first proposed, which demonstrated high survival (83.9-100\% up to 6 days post-treatment; Arregi et al. 2014). The spawning stock biomass for sardine in Cantabrian Sea and Atlantic Iberian waters (ICES divisions 8.c and 9.a) has been below safe biological limits since 2009, with ICES currently advising a zero TAC (in 2018) and Portuguese fisheries having at least a partial (seasonal) ban on catches. Therefore, although it would clearly be beneficial for this stock, fishers who responsibly release catches of sardines would be in breach of the LO. In another example, the EU CDR for pelagic fisheries in NW waters and the North Sea (EU 2014a, b) permits the slipping of mackerel and herring provided the release is completed 
before $80 \% / 90 \%$, respectively, of the net has been hauled ("the point of retrieval"). This contrasts with the Norwegian regulations for the mackerel fishery, which (following consultation with fishers and researchers) stipulate that the release opening must have been prepared before a comparable "point of release" $(87.5 \%$ [7/8th] of the net) but that the release may continue beyond this point; enabling the fishers to assess their catch and control the slipping operation. In addition, the Norwegian regulations stipulate how the catch should be released, i.e. through an opening sufficiently large to allow the released fish to swim out freely (NSFR 2014; Rule $\$ 48 \mathrm{a})$. These are practices that are already used in the Norwegian inshore purse seine fishery for transferring catches into holding cages (Breen et al. 2012) and that have been shown in work reviewed in this chapter to promote survival.

Another major challenge, shared by many fisheries, is monitoring fishing practices and ensuring compliance with the regulations (discussed in detail by Nuevo et al. (this volume)). Reliable estimates of slipping rates and any associated mortality would enable fisheries managers to account for this additional fishing mortality in stock assessments and any resultant advice on catch limits (e.g. Breen and Cook 2002; Mesnil 1996), as well as monitor the effects of slipping regulations on fishing practices. However, there are currently no known monitoring programmes targeting slipping practices. Furthermore, slipping practices will prove particularly challenging to monitor, because the catch is not taken aboard the vessel before it is released. Effective monitoring is likely to require on-board observers and/or electronic monitoring (EM). Even then methods for reliably characterising the status and species composition of the released catch are still to be developed. With regards to EM, the EU CDRs for pelagic fisheries in NW waters and the North Sea (EU 2014a, b) stipulate that all slipping operations should be monitored with an electronic recording system documenting when, where and the extent to which the net has been hauled. Interestingly, no commercially available technology currently exists to monitor purse seine hauling, effectively prohibiting all slipping operations in NW waters and the North Sea. Most concerning of all with regards to compliance, is that many fishers are yet to fully appreciate the implications of the LO (Maynou et al. 2018), although many do voluntarily take steps to avoid unwanted catches (Marçalo et al. 2018).

\subsection{Conclusion}

Management strategies and regulations currently attempting to address the slipping problem are, in reality, still in early development. Therefore, as we gain more knowledge in this area, management strategies are likely to require modifications to better suit the fisheries they are regulating. Furthermore, it is recognised that the successful implementation of fishing regulations is best done in close consultation with all stakeholders to ensure that what is prescribed is practical, safe, economically viable, effective and something that the fishers will actually implement (Karp et al., this volume). In terms of policy and research, priority should be given to avoiding 
UWC; avoidance is the most effective way of reducing slipping mortality and is likely to increase profitability for the fisher and therefore implementation. However, some level of UWC in purse seine fisheries for small pelagic species is inevitable. Methods for releasing UWC that promote high survival for the slipped catch must continue to be developed in collaboration with fishers to ensure they are practical, effective and implemented.

\section{References}

Arregi, L., Onandia, I., Ferarios, J.M., Ruiz J., Basurko, O.C. (2014). Assessing fish survival from slipping in purse seine fisheries of European southern waters. AZTI-Tecnalia, Sukarrieta (p. 44). [Report Presented to STECF Plenary 14-02].

Borges, T.C., Erzini, K., Bentes, L., Costa, M.E., Gonçalves, J.M.S., Lino, P.G., et al. (2001). By-catch and discarding practices in five Algarve (southern Portugal) métiers. Journal of Applied Ichthyology, 17, 104-114.

Breen, M., Isaksen, B., Ona, E., Pedersen, A.O., Pedersen, G., Saltskår, J., et al. (2012). A review of possible mitigation measures for reducing mortality caused by slipping from purse-seine fisheries. ICES CM 2012, C:12.

Breen, M., \& Cook, R. (2002). Inclusion of Discard and Escape Mortality Estimates in Stock Assessment Models and its likely impact on Fisheries Management. ICES CM 2002/N, 27, $15 \mathrm{pp}$.

Breen, M., Anders, N., Humborstad, O.-B., Nilsson, J., Tenningen, M., Vold, A. (In review). Catch welfare in commercial fisheries. In F. Kristiansen, \& Van de Vis Pavlidis (Eds.), Fish Welfare. Springer.

Breen, M., Saltskår, J., Anders, N., Totland, B., Øvredal, J.T., Tenningen, M., Handegard, N.O., Peña, H. (In review). A novel method for monitoring the behaviour of mackerel (Scomber scombrus) in relation to crowding and oxygen concentrations in commercial purse seine catches. Submitted to PLoS One.

Broadhurst, M.K., Suuronen, P., Hulme, A. (2006). Estimating collateral mortality from a towed fishing gear. Fish and Fisheries, 7, 180-218.

CRISP. (2018). CRISP: The Centre for Research-based Innovation in Sustainable fish capture and Processing technology. http://crisp.imr.no/en/projects/crisp/

DABGRAF. (2018). http://cmr.no/projects/10397/dabgraf/

Davis, M.W. (2002). Key principles for understanding fish bycatch discard mortality. Canadian Journal of Fisheries and Aquatic Sciences, 59, 1834-1843.

DGRM. (2017). DATAPESCAS. N $N^{\circ}$ 115/Janeiro-Dezembro 2017. Direção Geral dos Recursos Naturais, Segurança e Serviços Marítimos, Lisboa (p. 11).

Digre, H., Tveit, G.M., Solvang-Garten, T., Eilertsen, A., Aursand, I.G. (2016). Pumping of mackerel (Scomber scombrus) onboard purse seiners, the effect on mortality, catch damage and fillet quality. Fisheries Research, 176, 65-75.

EU. (2013). REGULATION (EU) No 1380/2013 OF THE EUROPEAN PARLIAMENT AND OF THE COUNCIL of 11 December 2013 on the Common Fisheries Policy, amending Council Regulations (EC) No 1954/2003 and (EC) No 1224/2009 and repealing Council Regulations (EC) No 2371/2002 and (EC) No 639/2004 and Council Decision 2004/585/EC.

EU. (2014a). Discard Plan for certain pelagic fisheries in north-western waters. Commission Delegated Regulation (EU), No 1393/2014.

EU. (2014b). Discard Plan for certain pelagic fisheries in the North Sea. Commission Delegated Regulation (EU) No 1395/2014. 
EU. (2014c). Discard Plan for certain pelagic fisheries in south-western waters, Commission Delegated Regulation (EU) 1394/2014.

Feijó, D., Marçalo, A., Bento, T., Barra, J., Marujo, D., Correia, M., Silva, A. (2018). Trends in the activity pattern, fishing yields, catch and landing composition between 2009 and 2013 from onboard observations in the Portuguese purse seine fleet. Regional Studies in Marine Science. Available online 1 January 2018, https://doi.org/10.1016/j.rsma.2017.12.007.

Gerlotto, F., \& Paramo, J. (2003). The three-dimensional morphology and internal structure of clupeid schools as observed using vertical scanning multibeam sonar. Aquatic Living Resources, $16,113-122$.

Gilman, E., Suuronen, P., Chaloupka, M. (2017). Discards in global tuna fisheries. Marine Ecology Progress Series, 582, 231-252. https://doi.org/10.3354/meps12340.

Gullestad, P., Blom, G., Bakke, G., Bogstad, B. (2015). The "Discard Ban Package": Experiences in efforts to improve the exploitation patterns in Norwegian fisheries. Marine Policy, 54, 1-9. https://doi.org/10.1016/j.marpol.2014.09.025.

Hall, M.A., Alverson, D.L., and Metuzals K.I. (2000). By-catch: Problems and solutions. Marine Pollution Bulletin, 41, 204-216.

Hall, M., \& Roman, M. (2013). Bycatch and non-tuna catch in the tropical tuna purse seine fisheries of the world. FAO Fisheries and Aquaculture Technical Paper No. 568. Rome, FAO (p. 249).

Handegard, N.O., Tenningen, M., Howarth, K., Anders, N., Rieucau, G., Breen, M. (2017, December). The loss of schooling function in mackerel in response to crowding but not hypoxia. PLoS ONE, 12(12), e0190259. https://doi.org/10.1371/journal.pone.0190259.

Holmin, A.J., Handegard, N.O., Korneliussen, R.J., Tjostheim, D. (2012). Simulations of multibeam sonar echos from schooling individual fish in a quiet environment. Journal of the Acoustical Society of America, 132, 3720-3734.

Horne, J.K. (2000). Acoustic approaches to remote species identification: An introductory review. Fisheries Oceanography, 9, 356-371.

Huse, I., and Vold A. (2010). Mortality of mackerel (Scomber scombrus L.) after pursing and slipping from a purse-seine. Fisheries Research, 106, 54-59.

ICES. (2016). Report of the Workshop on Methods for Estimating Discard Survival 5 (WKMEDS 5), 23-27 May 2016, Lorient, France. ICES CM 2016/ACOM:56 (p. 51).

ICES. (2018). Advice on fishing opportunities, catch, and effort. Bay of Biscay and the Iberian Coast Ecoregion pil.27.8c9a. https://doi.org/10.17895/ices.pub.4495.

ICES. (2018; In press). ICES WKMEDS Guidance on Method for Estimating Discard Survival. Breen, M. \& Catchpole, T. (Eds.). ICES Cooperative Research Report. In press.

Isaksen, B. (2013). Fish sampling by shooting a mini-trawl into the purse seine. IMR Marine Research News, 2-2013. https://www.hi.no/filarkiv/2013/07/hi_nytt_2_2013_til_web.pdf/en

Karp, W.A., Breen, M., Borges, L., Fitzpatrick, M., Kennelly, S.J., Kolding, J., et al. (this volume). Strategies used throughout the world to manage fisheries discards - Lessons for implementation of the EU Landing Obligation. In S.S. Uhlmann, C. Ulrich, S.J. Kennelly (Eds.), The European Landing Obligation - Reducing discards in complex, multi-species and multi-jurisdictional fisheries. Cham: Springer.

Kelleher, K. (2005). Discards in the world's marine fisheries. An update. FAO Fisheries Tech Paper, No. 470. Rome, FAO (p. 131).

Korneliussen, R.J., Heggelund, Y., Eliassen, I.K., and Johansen, G.O. (2009). Acoustic species identification of schooling fish. ICES Journal of Marine Science, 66, 1111-1118.

Larsen, T.A., \& Dreyer, B. (2013). Ringnot - Struktur og lønnsomhet. Tromsø: Nofima (ISBN 978-82-8296-111-0) 25, p. Nofima rapportserie (34/2013).

Lockwood, S.J., Pawson, M.G., and Eaton, D.R. (1983). The effects of crowding on mackerel (Scomber scombrus L.) physical condition and mortality. Fisheries Research, 2, 129-147.

LSSS. (2018). http://cmr.no/projects/10396/lsss/. Accessed 7 July 2018.

MAPAMA. (2017). Ministerio de Agricultura y Pesca, Alimentación y Medio Ambiente (MAPAMA), Estadísticas Pesqueras Noviembre 2017. Recovered 1/04/2018: http://www. mapama.gob.es/es/estadistica/temas/estadisticas-pesqueras/ 
Marçalo, A., Mateus, L, Correia, J.H.D., Serra, P., Fryer, R., Stratoudakis, Y. (2006). Sardine (Sardina pilchardus) stress reactions to purse-seine fishing. Marine Biology, 149, 1509-1518.

Marçalo, A. (2009). Sardine (Sardina pilchardus) delayed mortality associated with purse-seine slipping: contributing stressors and responses. Tese de doutoramento. Faculdade de Ciências e Tecnologia. Universidade do Algarve. 189pp.

Marçalo, A., Marques, T.A., Araújo, J., Pousão-Ferreira, P., Erzini, K., Stratoudakis, Y. (2010). Fishing simulation experiments for predicting effects of purse-seine capture on sardine (Sardina pilchardus). ICES Journal of Marine Science, 67, 334-344.

Marçalo, A., Guerreiro, P.M., Bentes, L., Rangel, M., Monteiro, P., Oliveira, F., Afonso, C., Pousão-Ferreira, P., Benoît, H., Breen, M., Erzini, K., Gonçalves, J.M.S. (2018). Effects of different slipping methods on the mortality of sardine, Sardina pilchardus, after purse-seine capture off the Portuguese Southern coast (Algarve). PLoS One, 13(5), e0195433. https://doi. org/10.1371/journal.pone.0195433.

Maynou, F., Gil, M.D.M., Vitale, S., Giusto, G.B., Foutsi, A., Rangel, M., Rainha, R., Erzini, K., Gonçalves, J.M.S., Bentes, L., Viva, C., Sartor, P., Carlo, F., Rossetti, I., Christou, M., Stergiou, K., Maravelias C.D., Damalas, D. (2018). Fishers' perceptions of the European Union discards ban: Perspective from south European fisheries. Marine Policy, 89, 147-153. https://doi.org/10. 1016/j.marpol.2017.12.019.

Megalofonou, P., Yannopoulos, C., Damalas, D., De Metrio, G., Deflorio, M., de la Serna, J.M., Macias, D.. (2005). Incidental catch and estimated discards of pelagic sharks from the swordfish and tuna fisheries in the Mediterranean Sea. Fisheries Bulletin, 103, 620-634.

Mesnil, B. (1996). When discards survive: Accounting for survival of discards in fisheries assessments. Aquatic Living Resources, 9, 209-215.

Mitchell, R.W., Blight, S.J., Gaughan, D.J., Wright, I.W. (2002). Does the mortality of released Sardinops sagax increase if rolled over the headline of a purse-seine net? Fisheries Research, 57, 279-285.

Nishimori, Y., Iida, K., Furusawa, M., Tang, Y., Tokuyama, K., Nagai, S., Nishiyama, Y. (2009). The development and evaluation of a three-dimensional, echo-integration method for estimating fish-school abundance. ICES Journal of Marine Science, 66, 1037-1042.

NSFR. (2014). Regulations relating to sea-water fisheries. Norwegian Ministry of Fisheries and Coastal Affairs. Amended 7th April 2014. https://www.fiskeridir.no/../20140407-regulationsrelating-to-sea-water-fisheries.pdf

Norwegian Fisheries Directorate DataBase. (2018). Fishers, fishing vessels and licenses. https:// www.fiskeridir.no/English/Fisheries/Statistics/Fishers-fishing-vessels-and-licenses. Accessed 7 July 2018.

O’Neill, F.G., Feekings, J., Fryer, R.J., Fauconnet, L., Afonso, P. (this volume). Discard avoidance by improving fishing gear selectivity: Helping the fishing industry help itself. In S.S. Uhlmann, C. Ulrich, S.J. Kennelly (Eds.), The European Landing Obligation - Reducing discards in complex, multi-species and multi-jurisdictional fisheries. Cham: Springer.

Peña, H., Saltskår, J., Totland, B., Vold, A., Breen, M., Ingolfsson, Ò.A., Tenningen, M. Øvredal, J.T. (2018). Purse Seine Catch Control. Final Project Report. Rapport fra Havforskningen 3-2018. (In Norwegian). https://www.hi.no/filarkiv/2017/12/3-2018-pscc_sluttrapp_av.pdf/nbno

Reid, D.G., Calderwood, J., Afonso, P., Fauconnet, L., Pawlowski, L., Plet-Hansen, K.S., et al. (this volume). The best way to reduce discards is by not catching them! In S.S. Uhlmann, C. Ulrich, S.J. Kennelly (Eds.), The European Landing Obligation - Reducing discards in complex, multi-species and multi-jurisdictional fisheries. Cham: Springer.

Rihan, D., Uhlmann, S.S., Ulrich, C., Breen, M., Catchpole, T. (this volume). Requirements for documentation, data collection and scientific evaluations. In S.S. Uhlmann, C. Ulrich, S.J. Kennelly (Eds.), The European Landing Obligation - Reducing discards in complex, multi-species and multi-jurisdictional fisheries. Cham: Springer.

SEAT. (2018). http://cmr.no/projects/10414/seat/. Accessed 7 July 2018.

STECF. (2014). Scientific, Technical and Economic Committee for Fisheries (STECF) - 46th Plenary Meeting Report (PLEN-14-02). 2014. Publications Office of the European Union, Luxembourg, EUR 26810 EN, JRC 91540, 117 pp. 
STECF. (2017). Scientific, Technical and Economic Committee for Fisheries - The 2017 Annual Economic Report on the EU Fishing Fleet (STECF-17-12). Publications Office of the European Union, Luxembourg, 2017, ISBN 978-92-79-73426-7. https://doi.org/10.2760/36154, PUBSY No. JRC107883.

Silva, A., Moreno, A., Riveiro, I., Santos, B., Pita, C., Rodrigues, J.G. et al. (2015). Research for Pech Committee- Sardine Fisheries. Resource Assessment and Social and Economic Situation. Directorate- General for Internal Policies IP/B/PECH/IC/2015_133.

SINTEF FKiN Project. (2018). Catch control in purse seine fishing. https://www.sintef.no/ fangstkontroll

Stratoudakis, Y., \& Marçalo, A. (2002). Sardine slipping during purse-seining off northern Portugal. ICES Journal of Marine Science, 59, 1256-1262.

Tenningen, M., Vold, A., Olsen, R.E. (2012). The response of herring to high crowding densities in purse-seines: Survival and stress reaction. ICES Journal of Marine Science, 69, 1523-1531.

Tenningen, M., Macaulay, G.J., Rieucau, G., Pena, H., Korneliussen, R.J. (2017). Behaviours of Atlantic herring and mackerel in a purse-seine net, observed using multibeam sonar. ICES Journal of Marine Science, 74, 359-368.

Tenningen, M., Pena, H., Macaulay, G.J. (2015). Estimates of net volume available for fish shoals during commercial mackerel (Scomber scombrus) purse seining. Fisheries Research, 161, 244-251.

Vatnehol, S., Pena, H., Ona, E. (2017). Estimating the volumes of fish schools from observations with multi-beam sonars. ICES Journal of Marine Science, 74, 813-821.

Veiga, P., Pita, C., Rangel, M., Gonçalves, J.M.S., Campos, A., Fernandes, P.G., et al. (2016). The EU landing obligation and European small-scale fisheries: What are the odds for success? Marine Policy, 64, 64-71.

Villasante, S., Pierce, G.J., Pita, C., Guimeráns, C.P., Rodrigues J.G., Antelo, M., et al. (2016a). Fishers' perceptions about the EU discards policy and its economic impact on small-scale fisheries in Galicia (North West Spain). Ecological Economics, 130, 130-138.

Villasante, S., Pita, C., Pierce, G.J., Guimeráns, C.P., Rodrigues, J.G., Antelo, M., et al. (2016b). To land or not to land: How do stakeholders perceive the zero discard policy in European smallscale fisheries? Marine Policy, 71, 166-174.

Vold, A., Anders, N., Breen, M., Saltskår, J., Totland B. og Øvredal J.T. (2017). Beste praksis for slipping fra not. Utvikling av standard slippemetode for makrell og sild i fiske med not. Faglig sluttrapport for FHF-prosjekt 900999. Rapport fra Havforskningen nr. 6 2017. ISSN 1893-4536 (online).

Watson, R., Revenga, C. \& Kura, Y. (2006). Fishing gear associated with global marine catches. I Database development. Fisheries Research, 79(1-2), 97-102.

Open Access This chapter is licensed under the terms of the Creative Commons Attribution 4.0 International License (http://creativecommons.org/licenses/by/4.0/), which permits use, sharing, adaptation, distribution and reproduction in any medium or format, as long as you give appropriate credit to the original author(s) and the source, provide a link to the Creative Commons license and indicate if changes were made.

The images or other third party material in this chapter are included in the chapter's Creative Commons license, unless indicated otherwise in a credit line to the material. If material is not included in the chapter's Creative Commons license and your intended use is not permitted by statutory regulation or exceeds the permitted use, you will need to obtain permission directly from the copyright holder.



